\title{
PRODUÇÃO DE MATÉRIA SECA E ACÚMULO DE MACRONUTRIENTES NA PARTE AÉREA DAS PLANTAS DE NIGER
}

\author{
Munir Mauad(1)*, Rodrigo Arroyo Garcia(2), Rosilda Mara Mussury Franco Silva(3), Thiago \\ Alexandre Freire da Silva(1), Igor Miguel Schroeder(1), Carlos Henrique Knudsen(1) e Elias \\ Vinicius Wanderlinde Quaresma(1)
}

(1) Universidade Federal da Grande Dourados, Faculdade de Ciências Agrárias, Dourados, Mato Grosso do Sul, Brasil.
(2) Empresa Brasileira de Pesquisa Agropecuária, Dourados, Mato Grosso do Sul, Brasil.
(3) Universidade Federal da Grande Dourados, Faculdade de Ciências Biológicas e Ambientais, Mato Grosso do Sul, Brasil.
*Autor correspondente.
E-mail: munirmauad@ufgd.edu.br

\begin{abstract}
RESUMO
O estudo da marcha de absorção de nutrientes e da produção de matéria seca em razão do estádio de desenvolvimento das culturas é de fundamental importância para subsidiar estratégias de adubação. Este trabalho objetivou determinar a produção de matéria seca e o acúmulo de macronutrientes na parte aérea das plantas de Guizotia abyssinica (niger), em diferentes estádios de crescimento e desenvolvimento. $O$ delineamento experimental foi em blocos ao acaso, com cinco repetições. Amostras da parte aérea das plantas foram coletadas aos 15, 30, 45, 60, 75 e 90 dias após a emergência (DAE). Em cada coleta, as plantas foram divididas em folha, caule + ramos, capítulo e aquênios (grãos), secas até peso constante para posterior determinação da massa de matéria seca e teor de N, P, K, Ca, Mg e S. Os teores dos macronutrientes na parte aérea das plantas de niger, seguiram a seguinte ordem de exportação de nutrientes: $\mathrm{N}>\mathrm{Ca}>\mathrm{Mg}>\mathrm{P}>\mathrm{K}>\mathrm{S}$. Em contrapartida, quanto aos teores dos nutrientes nos grãos por ocasião da colheita do experimento, a quantidade dos elementos exportados seguiu a ordem: $\mathrm{N}>\mathrm{P}>\mathrm{Ca}>\mathrm{Mg}>\mathrm{S}>\mathrm{K}$. Atenção especial deve ser dada à manutenção da adequada disponibilidade de $\mathrm{N}$ e $\mathrm{P}$ nas fases inicias por causa do ciclo curto e do rápido surgimento das estruturas reprodutivas. A exportação de nutrientes e o índice de colheita são baixos para as plantas de niger, resultando maior oferta de nutrientes para o cultivo em rotação.
\end{abstract}

Palavras-chave: Guizotia abyssinica, marcha de absorção, macronutrientes, biodiesel. 


\title{
ABSTRACT: SHOOT DRY MATTER AND SHOOT MACRONUTRIENT ACCUMULATION IN NIGER
}

\begin{abstract}
Studying nutrient uptake and dry matter accumulation in plants as affected by crop developmental stages is essential to establish and assist strategies for crop fertilization. The aim of this study was to assess shoot dry matter and macronutrient accumulation in Guizotia abyssinica (niger) at different growth and development stages. A randomized block experimental design with five replications was used. Shoot samples of the plants were taken at 15, 30, 45, 60, 75, and 90 days after seedling emergence (DAE). At each sampling, plants were separated into leaves, stem + branches, flower heads, and achenes. The samples were then dried until reaching constant weight to evaluate dry matter and $N, P, K, C a$, $M g$, and $S$ contents. Macronutrient concentration in niger shoots showed the following order of nutrient export: $N>C a>M g>P>K>S$. Conversely, concentration in achenes at harvest followed the order $N>P>C a>M g>S>K$. Special attention must be paid to maintaining appropriate availability of $N$ and $P$ in initial growth stages due to the short developmental cycle and early flowering of niger. Nutrient export and harvest index are low in niger plants, resulting in a higher nutrient supply for the crop in rotation.
\end{abstract}

Keywords: Guizotia abysinica, nutrient uptake rate, biodiesel.

\section{INTRODUÇÃO}

O estudo da marcha de absorção de nutrientes e da produção de matéria seca por causa do estádio de desenvolvimento das culturas é de fundamental importância para subsidiar estratégias de definição das quantidades e das épocas de realizações de adubação e das quantidades mínimas que devem ser restituídas ao solo para fins de manutenção da fertilidade. Isso contribui para o aumento da eficiência no manejo das culturas, proporcionando ganhos em produtividade e redução de custos, com o consequente uso racional e eficiente dos insumos aplicados no solo (Franco, 2011).

O niger (Guizotia abyssinica), uma oleaginosa da família das Asteraceae, nativa da Africa, tem grande potencial para produção de óleo comestível de alta qualidade, pois, além do elevado teor de óleo (30 a $45 \%$ ), apresenta excelente qualidade do perfil de ácidos graxos poli-insaturados, composto principalmente pelo ácido linoleico, cerca de 70 \% (Ramdan e Morsel, 2003). O ácido linoleico desempenha importante função na estrutura das membranas celulares e nos processos metabólicos, como a redução dos riscos de doenças cardiovasculares, por meio das melhorias dos teores de triglicérides, colesterol total e da lipoproteína de baixa densidade (Fagherazi et al., 2008). A utilização do óleo de niger está ligada à fonte de proteína na dieta humana, à indústria química na produção de sabonetes, tintas lubrificantes e biodiesel (Sarin et al., 2009).

O niger é uma planta dicotiledônea herbácea anual, que pode atingir um porte de 0,5-1,5 m de altura. Suas folhas são opostas, sésseis, ovaladas-lanceoladas, serrilhadas, podendo atingir em torno de $22 \mathrm{~cm}$ de comprimento. Já suas flores são amarelas, a polinização é cruzada, realizada por abelhas (Getinet e Sharma, 1996; Bessa et al.,
2008). As sementes são negras brilhantes, e muito leves, com peso de 1.000 sementes variando de 3 a 5 g (Ramdan e Morsel, 2002).

Essa espécie é cultivada com sucesso em sistemas de rotação com a soja, milho e trigo (Getinet e Sharma, 1996) e tem sido estudada no Brasil como alternativa para compor sistema de rotação de cultura na safrinha, em regiões onde o período de semeadura de culturas tradicionais como o milho é limitado por restrições térmicas e hídricas (Ambrosano, 2012; Franchini, 2014). Contudo, ainda não há informações disponíveis na literatura sobre a demanda por nutrientes pela cultura do niger. Nesse aspecto, o conhecimento da marcha de absorção dos nutrientes pelo niger é essencial para definir as estratégias de adubação para obter elevados rendimentos por essa cultura (Zobiole et al., 2010).

Objetivou-se com este trabalho determinar a produção de matéria seca e o acúmulo de macronutrientes na parte aérea das plantas de Guizotia abyssinica (niger), em diferentes estádios de crescimento e desenvolvimento.

\section{MATERIAL E MÉTODOS}

O experimento foi realizado na Fazenda Experimental de Ciências Agrárias da Universidade Federal da Grande Dourados (UFGD), município de Dourados, MS, localizado nas coordenadas geográficas de $54^{\circ} 56^{\prime} \mathrm{W}$ e $22^{\circ}$ 12 ' $\mathrm{S}$ e a $452 \mathrm{~m}$ de altitude. O clima conforme a classificação de Köppen é do tipo Cwa, que se caracteriza como mesotérmico úmido com verão chuvoso. As precipitações pluviais e as temperaturas médias, registradas durante a realização do experimento, estão apresentadas 
na figura 1. O solo da área experimental foi classificado como Latossolo Vermelho distroférrico muito argiloso (Embrapa, 2013), apresentando nos $20 \mathrm{~cm}$ superficiais $\mathrm{MO}: 23,6 \mathrm{~g} \mathrm{dm}^{-3} ; \mathrm{pH}\left(\mathrm{CaCl}_{2}\right)$ : 5,9; $\mathrm{P}($ resina $): 16,6 \mathrm{mg} \mathrm{dm}^{-3} ; \mathrm{K}^{+}, \mathrm{Ca}^{2+} \mathrm{e} \mathrm{Mg}^{2+}: 5,6$; 57,4 e $19,5 \mathrm{mmol}_{\mathrm{c}} \mathrm{dm}^{-3}$, respectivamente; $\mathrm{S}_{-} \mathrm{SO}_{4}{ }^{-2}$ : $6,6 \mathrm{mg} \mathrm{dm}^{-3} \mathrm{e} \mathrm{V}=76 \%$. A análise granulométrica do solo desta camada revelou valores de: $644,203 \mathrm{e}$ $152 \mathrm{~g} \mathrm{~kg}^{-1}$ de argila, silte e areia, respectivamente.

$\mathrm{O}$ delineamento experimental foi em blocos ao acaso, com seis épocas de coleta $(15,30,45,60$, 75 e 90 dias, após a emergência das plântulas) e cinco repetições, totalizando 30 unidades experimentais. A semeadura do niger foi realizada em maio de 2013, utilizando-se uma semeadora-adubadora de 13 linhas. A adubação foi de $300 \mathrm{~kg} \mathrm{ha}^{-1}$ da fórmula 08-20-20 de NPK.

Cada unidade experimental foi constituída de seis linhas de 10,0 m de comprimento, espaçadas entre si por $0,45 \mathrm{~m}$ e densidade de semeadura de 10 plantas $\mathrm{m}^{-1}$. A área útil foi constituída de quatro linhas centrais, desprezando-se 1,0 m em ambas as extremidades.

Amostras da parte aérea das plantas foram coletadas aos $15,30,45,60,75$ e 90 dias, após a emergência (DAE). Em cada metro de linha, foram coletadas 10 plantas. A cada coleta, as plantas foram divididas em folha (limbo e pecíolo), caule + ramos, capitulo e aquênios. As diversas partes das plantas foram lavadas e secas em estufa de circulação forçada de ar a $65{ }^{\circ} \mathrm{C}$, até atingirem peso constante. Em seguida, quantificou-se o peso da matéria seca das amostras e essas foram moídas em moinho tipo Willey. O teor de N, P, K, Ca, Mg e S no tecido vegetal foi determinada em cada parte da planta, de acordo com os procedimentos propostos por Malavolta et al. (1997).

$\mathrm{O}$ acúmulo de matéria seca e dos nutrientes, em cada estrutura da planta e na planta inteira em função dos dias após a semeadura foram ajustados ao modelo Gaussian com três parâmetros (Zobiole et al., 2010), descrito a partir da equação 1 :

$$
\hat{y}=a e^{[-0,5(x-x 0 / b) 2]}
$$

em que y é o acúmulo de nutrientes; a, o valor de máximo acúmulo; $\mathrm{x}_{0}$, o valor de $\mathrm{x}$, em $\mathrm{DAE}$, que proporciona o máximo em $\hat{y}$; e $b$, a amplitude no valor de $\mathrm{x}$, em DAE, entre o ponto de inflexão e o ponto de máximo. Assim, a partir do modelo ajustado, foi possível determinar, com exatidão, o valor do ponto de inflexão (PI) na curva de acordo com a equação 2 :

$$
\mathrm{PI}=\mathrm{x}_{0}-\mathrm{b}
$$

Matematicamente, o PI corresponde ao valor de $\mathrm{x}$ em que a curvatura do modelo ajustado muda de sinal; fisiologicamente, isso corresponde ao valor de $\mathrm{x}$, em DAE, em que a taxa de acúmulo diário, ainda que positiva, passa a decrescer.

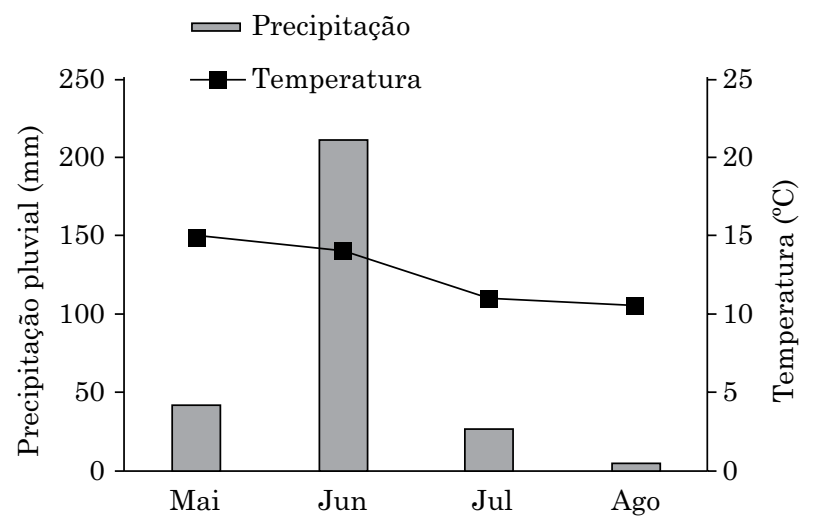

Figura 1. Precipitação pluvial mensal e temperatura média no período experimental. Fonte: Estação Agrometereológica Embrapa Agropecuária Oeste, Dourados, MS.

\section{RESULTADO E DISCUSSÕES}

A produção de massa seca das plantas de niger foi lenta até o $30^{\circ} \mathrm{DAE}$ (Figura 1), com folhas e colmos contribuindo com percentuais próximos (47,1 e 42,1\%, respectivamente) para o incremento de massa de matéria seca nesse período. Essa observação pode ser explicada pela forma de roseta adquirida pela planta, com grande número de folhas expandidas e entrenós curtos.

A partir dos $30 \mathrm{DAE}$, os colmos + ramos começam a contribuir de forma mais intensa para a produção de matéria seca total (Figura 2), sendo o valor máximo dessas estruturas alcançado aos 73 dias após a emergência das plântulas, com 7,50 g/planta (Figura 2, Quadro 1). Esse comportamento é explicado pelo início do crescimento das ramificações que brotaram das axilas das folhas do colmo principal. Constatação similar foi relatada por Ambrosano (2012), o qual verificou intenso crescimento das ramificações e do diâmetro de colmo de plantas de niger no período de 30 a 60 DAE, em Lavras, MG.

A produção máxima de matéria seca da planta inteira ocorreu aos 76 dias com $14,51 \mathrm{~g}$ (Quadro 1, Figura 2). Para os grãos, a produção máxima foi alcançada aos 82 dias após a emergência, com 1,16 g/planta. Tomando-se como base os teores dos macronutrientes no final do experimento, na planta inteira e nos aquênios (Quadro 2), observou-se, respectivamente, a ordem: $\mathrm{N}>\mathrm{Ca}>\mathrm{Mg}>\mathrm{P}>\mathrm{K}>\mathrm{S}$ e $\mathrm{N}>\mathrm{P}>\mathrm{Ca}>\mathrm{Mg}>\mathrm{S}>\mathrm{K}$. De acordo com os teores de nutrientes nos aquênios do niger (Quadro 2) e massa de matéria seca dos aquênios, verificou-se exportação de nutrientes na ordem de 8,66;2,23;0,45;1,20;0,90; e $0,66 \mathrm{~kg} \mathrm{ha}^{-1}$ para $\mathrm{N}, \mathrm{P}, \mathrm{K}, \mathrm{Ca}, \mathrm{Mg}$ e $\mathrm{S}$, respectivamente. A produtividade de grãos foi de $258 \mathrm{~kg} \mathrm{ha}^{-1}$. Essa produtividade ficou dentro dos valores 
Quadro 1. Estimativa dos parâmetros das equações de regressões de acordo com o modelo Gaussian ajustadas para a produção de matéria seca e o acúmulo de macronutrientes nas diferentes estruturas da parte aérea de plantas de niger em função do tempo (dia) desde a emergência e os respectivos tempos em que ocorreu o ponto de inflexão

\begin{tabular}{|c|c|c|c|c|c|}
\hline \multirow{2}{*}{ Parte da planta } & \multicolumn{3}{|c|}{ Estimativa dos parâmetros do modelo } & \multirow{2}{*}{$\begin{array}{c}P I \\
\left(x_{0}-b\right)\end{array}$} & \multirow{2}{*}{$R^{2}$ ajustado } \\
\hline & $\mathbf{a}$ & $\mathrm{x}_{0}$ & $\mathbf{b}$ & & \\
\hline & g/planta & & Dias após emergência & & \\
\hline & & & Matéria seca & & \\
\hline Folha & 3,11 & 65,46 & 24,37 & 41,09 & $0,89^{* * *}$ \\
\hline Colmo + Ramos & 7,50 & 73,13 & 23,53 & 49,60 & $0,83^{* *}$ \\
\hline Capítulo & 3,19 & 90,38 & 30,21 & 60,71 & $0,96^{* *}$ \\
\hline Aquênio & 1,16 & 81,74 & 13,63 & 68,11 & $0,99^{* * *}$ \\
\hline \multirow[t]{2}{*}{ Planta inteira } & 14,51 & 95,81 & 25,38 & 50,43 & $0,90^{*}$ \\
\hline & $\mathrm{mg} /$ planta & & Nitrogênio & & \\
\hline Folha & 110,01 & 62,22 & 26,43 & 35,80 & $0,70^{*}$ \\
\hline Colmo + Ramos & 190,10 & 50,53 & 90,30 & 41,50 & $0,70^{*}$ \\
\hline Capítulo & 75,20 & 92,87 & 34,46 & 58,41 & $0,88^{* *}$ \\
\hline Aquênio & 58,74 & 80,82 & 13,23 & 67,59 & $0,99^{* *}$ \\
\hline \multirow[t]{2}{*}{ Planta inteira } & 321,74 & 69,50 & 25,02 & 44,48 & $0,69^{*}$ \\
\hline & & & Fósforo & & \\
\hline Folha & 10,14 & 61,59 & 21,71 & 39,88 & $0,86^{* *}$ \\
\hline Colmo + Ramos & 20,70 & 61,21 & 17,80 & 43,41 & $0,68^{*}$ \\
\hline Capítulo & 17,73 & 73,90 & 21,70 & 52,20 & $0,98^{* *}$ \\
\hline Aquênio & 15,88 & 80,35 & 13,12 & 67,23 & $0,99^{* *}$ \\
\hline \multirow[t]{2}{*}{ Planta inteira } & 53,36 & 71,72 & 21,61 & 50,11 & $0,93^{* *}$ \\
\hline & & & Potássio & & \\
\hline Folha & 9,19 & 58,40 & 23,73 & 34,67 & $0,75^{*}$ \\
\hline Colmo + Ramos & 20,26 & 65,90 & 22,22 & 43,68 & $0,85^{* *}$ \\
\hline Capítulo & 9,07 & 94,80 & 32,55 & 62,25 & $0,95^{* *}$ \\
\hline Aquênio & 2,80 & 80,05 & 14,60 & 65,45 & $0,99 * *$ \\
\hline \multirow[t]{2}{*}{ Planta inteira } & 37,03 & 69,45 & 25,66 & 43,79 & $0,86^{* *}$ \\
\hline & & & Cálcio & & \\
\hline Folha & 84,96 & 62,84 & 19,19 & 43,65 & $0,87^{* *}$ \\
\hline Colmo + Ramos & 79,02 & 67,80 & 16,92 & 50,88 & $0,82^{*}$ \\
\hline Capítulo & 42,11 & 82,38 & 24,28 & 58,10 & $0,98^{* *}$ \\
\hline Aquênio & 8,10 & 81,64 & 14,59 & 67,05 & $0,99 * *$ \\
\hline \multirow[t]{2}{*}{ Planta inteira } & 201,16 & 68,77 & 21,37 & 47,40 & $0,88^{* *}$ \\
\hline & & & Magnésio & & \\
\hline Folha & 17,22 & 63,65 & 21,13 & 42,52 & $0,90^{* *}$ \\
\hline Colmo + Ramos & 35,72 & 66,78 & 17,87 & 48,91 & $0,88^{* *}$ \\
\hline Capítulo & 12,91 & 83,74 & 25,56 & 58,18 & $0,98^{* *}$ \\
\hline Aquênio & 6,38 & 80,41 & 12,97 & 67,44 & $0,99 * *$ \\
\hline \multirow[t]{2}{*}{ Planta inteira } & 66,93 & 69,81 & 28,84 & 48,97 & $0,92^{* *}$ \\
\hline & & & Enxofre & & \\
\hline Folha & 15,34 & 61,91 & 18,51 & 43,30 & $0,84^{*}$ \\
\hline Colmo + Ramos & 22,94 & 61,05 & 16,27 & 44,78 & $0,77^{*}$ \\
\hline Capítulo & 9,14 & 78,15 & 23,86 & 54,29 & $0,98^{* *}$ \\
\hline Aquênio & 5,26 & 78,60 & 12,95 & 65,65 & $0,98^{* *}$ \\
\hline Planta inteira & 47,23 & 66,05 & 20,18 & 45,87 & $0,85^{* *}$ \\
\hline
\end{tabular}

** $\mathrm{e} *$ : significativo a 1 e $5 \%$ pelo teste $\mathrm{F}$, respectivamente. 
Quadro 2. Teores médios de N, P, K, Ca, Mg e S na planta inteira e nos componentes da parte aérea de planta de niger em função dos dias após a emergência (DAE)

\begin{tabular}{|c|c|c|c|c|c|c|}
\hline DAE & $\mathbf{N}$ & $\mathbf{P}$ & $\mathbf{K}$ & $\mathbf{C a}$ & Mg & $\mathrm{S}$ \\
\hline & \multicolumn{6}{|c|}{ g kg-1 } \\
\hline \multicolumn{7}{|c|}{ Folhas } \\
\hline 15 & 63,28 & 4,24 & 5,13 & 13,34 & 3,66 & 2,96 \\
\hline 30 & 39,20 & 2,25 & 3,98 & 17,54 & 4,30 & 2,43 \\
\hline 45 & 46,48 & 3,93 & 3,73 & 24,79 & 5,41 & 4,62 \\
\hline 60 & 36,40 & 3,26 & 3,11 & 27,45 & 5,44 & 5,02 \\
\hline 75 & 25,48 & 2,64 & 1,96 & 22,76 & 5,14 & 3,65 \\
\hline 90 & 38,92 & 2,80 & 2,46 & 20,06 & 4,51 & 3,21 \\
\hline \multicolumn{7}{|c|}{ Colmo + Ramos } \\
\hline 15 & 35,28 & 3,79 & 7,08 & 15,38 & 4,27 & 3,87 \\
\hline 30 & 19,32 & 1,73 & 4,93 & 10,87 & 3,98 & 3,47 \\
\hline 45 & 16,52 & 2,22 & 3,90 & 10,71 & 4,50 & 4,03 \\
\hline 60 & 22,68 & 2,60 & 2,76 & 11,06 & 4,78 & 3,19 \\
\hline 75 & 7,00 & 1,38 & 2,49 & 9,81 & 4,54 & 1,87 \\
\hline 90 & 10,64 & 1,34 & 2,08 & 7,99 & 2,18 & 1,60 \\
\hline \multicolumn{7}{|c|}{ Capítulo } \\
\hline 30 & 32,48 & 6,34 & 2,98 & 9,72 & 3,36 & 2,80 \\
\hline 45 & 31,88 & 6,95 & 2,84 & 11,42 & 3,83 & 3,37 \\
\hline 60 & 25,20 & 6,68 & 2,73 & 13,20 & 3,97 & 3,40 \\
\hline 75 & 20,27 & 6,75 & 2,65 & 15,08 & 4,54 & 3,41 \\
\hline 90 & 24,36 & 4,24 & 2,83 & 12,66 & 3,93 & 2,54 \\
\hline \multicolumn{7}{|c|}{ Aquênio } \\
\hline 60 & 36,96 & 10,34 & 2,48 & 5,93 & 3,98 & 4,00 \\
\hline 75 & 35,28 & 9,83 & 1,81 & 5,09 & 3,91 & 3,47 \\
\hline 90 & 33,60 & 8,63 & 1,61 & 5,01 & 3,50 & 2,56 \\
\hline \multicolumn{7}{|c|}{ Planta inteira } \\
\hline 15 & 57,97 & 4,16 & 5,50 & 13,72 & 3,78 & 3,13 \\
\hline 30 & 30,17 & 2,54 & 4,27 & 13,79 & 4,02 & 2,91 \\
\hline 45 & 28,68 & 3,61 & 3,66 & 15,36 & 4,67 & 4,12 \\
\hline 60 & 26,73 & 3,68 & 2,83 & 15,21 & 4,79 & 3,39 \\
\hline 75 & 16,79 & 3,74 & 2,34 & 12,91 & 4,60 & 2,74 \\
\hline 90 & 20,93 & 3,05 & 2,28 & 10,62 & 3,50 & 2,19 \\
\hline
\end{tabular}

relatados na literatura para essa espécie, de 200 a $300 \mathrm{~kg} \mathrm{ha}^{-1}$ (Getinet e Sharma, 1996). Nesse sentido, informações referentes às quantidades de nutrientes extraídos e exportados via grãos são relevantes para o programa de recomendações de adubação (Werle et al., 2008).

Os teores de $\mathrm{N}$ nas plantas de niger foram elevadas desde as fases iniciais de desenvolvimento, evidenciando a importância da disponibilidade de $\mathrm{N}$ às plantas por ocasião da semeadura (Quadro 2). No caso das folhas, aos 15 dias após a emergência (DAE), o teor de $\mathrm{N}$ foi de $63,28 \mathrm{~g} \mathrm{~kg}^{-1}$, com posterior decréscimo ao longo do desenvolvimento das plantas,

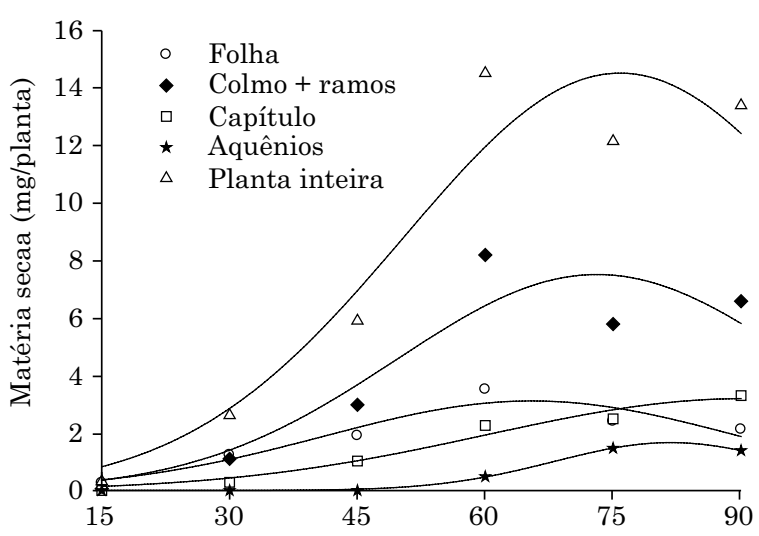

Figura 2. Produção de matéria seca da parte aérea das plantas de niger em função dos dias após a emergência (DAE).

visto que outras estruturas das plantas começaram a se desenvolver, como os capítulos e aquênios (Figura 2). Como o início da formação das estruturas reprodutivas é relativamente rápido, aos 30 dias após a emergência, acredita-se que, logo nas fases iniciais de desenvolvimento das folhas, as plantas acumularam $\mathrm{N}$ para suprir a posterior demanda dos capítulos e aquênios.

O crescimento vegetativo promoveu o desenvolvimento rápido da área foliar e com isso a formação de um aparto fotossintético capaz de suportar rendimentos elevados. As plantas de niger também podem ter acumulado proteínas de armazenamento vegetativo que poderão posteriormente ser translocadas para os grãos. Staswick et al. (1991) e Staswick (1994) relataram a importância de proteínas armazenadas nos tecidos vegetativos, que servem para armazenar $\mathrm{N}$ durante condições de suprimento adequado desse nutriente e que, durante o enchimento de grãos, é redistribuído para esses órgãos. Um fator que pode ter contribuído para esses valores elevados de $\mathrm{N}$ no tecido vegetal é que, entre as dicotiledôneas, normalmente as espécies da família Asteraceae apresentam as maiores quantidades de frutano, que, depois do amido e da sacarose, é o carboidrato mais distribuído nos vegetais (Meier e Reid, 1982). A elevação nos teores de frutano sugere aumento nas atividades das enzimas de síntese, evidenciando a participação do $\mathrm{N}$ nesse processo (Taiz e Zeiger, 2013).

Quanto ao acúmulo de $\mathrm{N}$ na parte aérea das plantas (Figura 3), as folhas e os colmos foram responsáveis pelo armazenamento de grande parte do $\mathrm{N}$ extraído até os $60 \mathrm{DAE}$. Além dos elevados teores nessas estruturas das plantas até esse período (Quadro 2), a contribuição na produção de fitomassa também foi maior (Figura 2 ), ocasionando maiores quantidades de $\mathrm{N}$ 
(a)

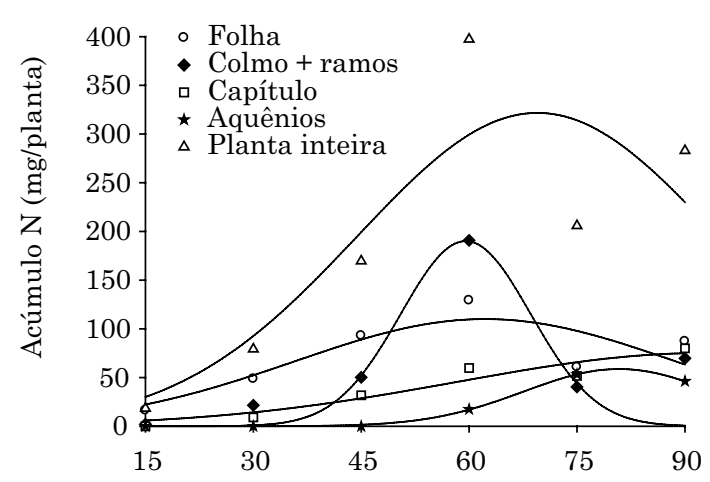

(c)

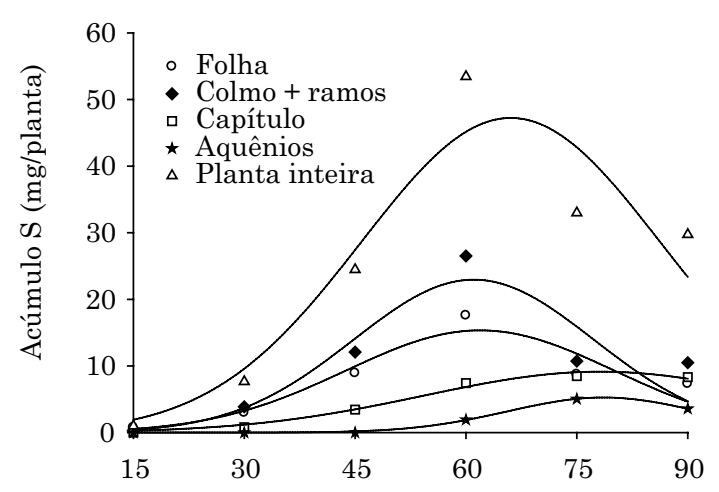

(e)

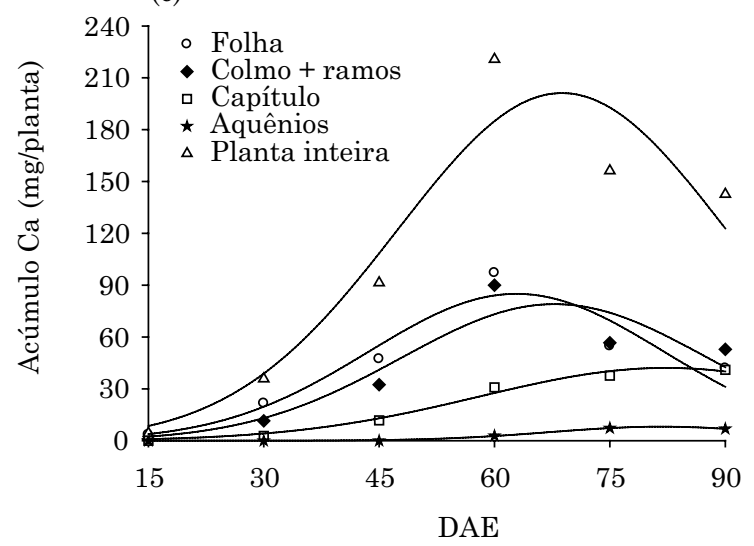

(b)

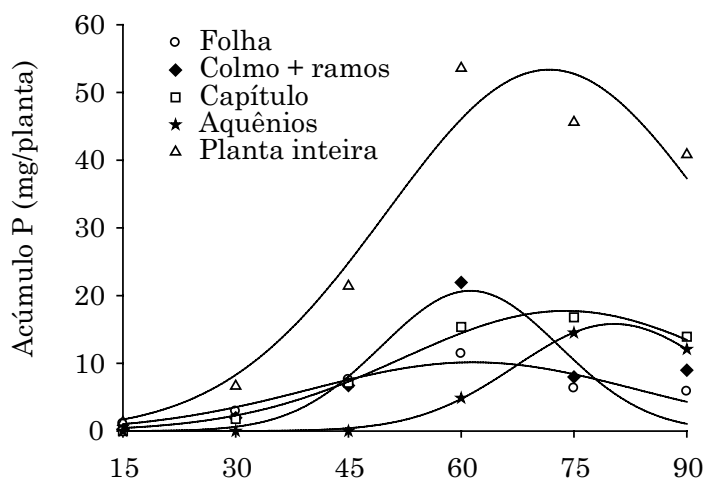

(d)

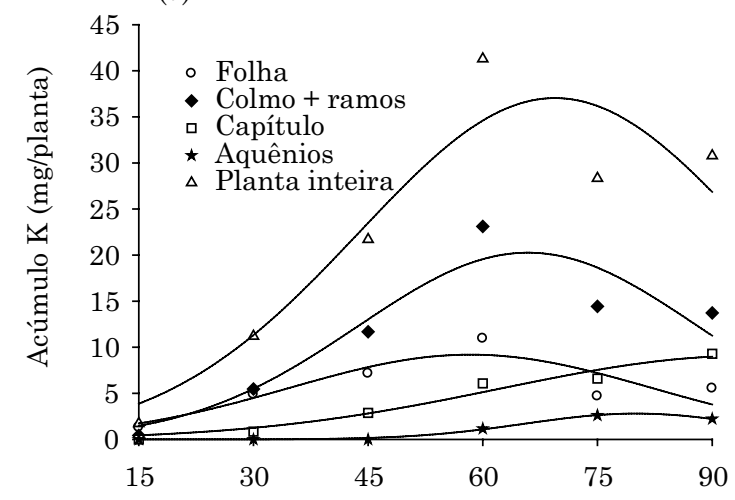

(f)

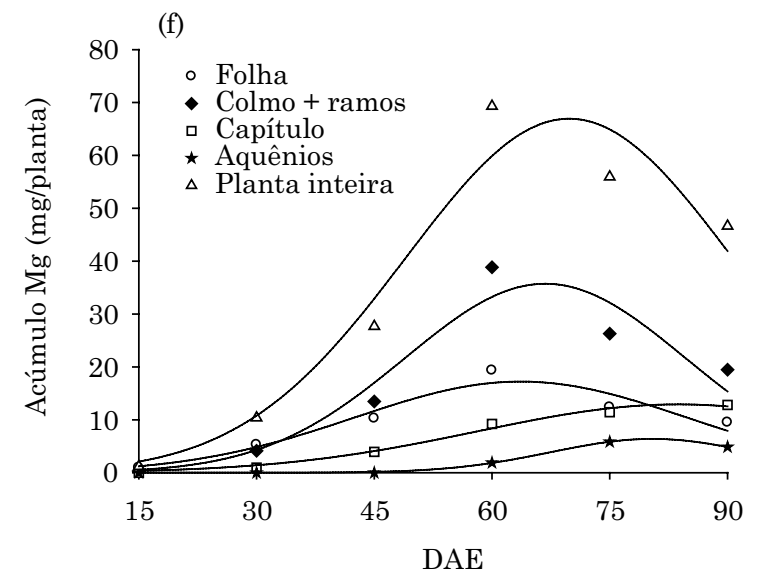

Figura 3. Acúmulo de nitrogênio, fósforo, enxofre, potássio, cálcio e magnésio na planta inteira e nos diferentes componentes da parte aérea das plantas de niger em função dos dias após emergência (DAE).

armazenadas nas folhas e nos colmos. A partir dos 60 DAE, fica evidente a contribuição das estruturas vegetativas com nitrogênio para a formação dos capítulos e grãos das plantas de niger. De acordo com Marschner (2012), o N é um elemento móvel na planta e transloca-se facilmente de um órgão para outro; no florescimento é o período em que há maior translocação da parte aérea para a inflorescência. Contudo, a translocação depende de vários fatores, entre eles do teor de $\mathrm{N}$ na parte aérea, que no caso do niger nesta pesquisa foi alta, intensificando esse processo (Quadro 2).

Para o $\mathrm{P}$, o máximo acúmulo considerando a planta inteira foi de $53,36 \mathrm{mg} /$ planta e ocorreu aos $72 \mathrm{DAE}$, enquanto para o capítulo e aquênio ocorreram aos 74 e 80 DAE, com 17,73 e 15,52 mg/planta, respectivamente (Quadro 3). Comportamento similar às plantas inteiras foi detectado para os acúmulos de $\mathrm{P}$ nas folhas e nos caules + ramos, obtidos próximo aos $62 \mathrm{DAE}$, o que coincide com o início da maturação dos aquênios, proveniente 
dos primeiros capítulos que surgiram $30 \mathrm{DAE}$ (Figura 2). O niger produz vários capítulos em suas ramificações; assim como o início do florescimento aos 30 DAE (Figura 2), os primeiros aquênios chegaram à maturação cerca de 30 após o surgimento dos capítulos, ou seja, 60 DAE. Nesse momento, há na planta de niger capítulos e aquênios em diferentes estádios de desenvolvimento. O máximo acúmulo determinado a partir do modelo ajustado ocorreu aos 61 e 68 dias para a produção de matéria seca de capítulo e aquênios, respectivamente (Quadro 1), enquanto para o acúmulo de $\mathrm{P}$ foi aos 52 e 67 dias para os capítulos e os aquênios, respectivamente (Quadro 3). Esses resultados evidenciaram grande demanda por $\mathrm{P}$ a partir do surgimento dos primeiros capítulos (30 DAE) e se intensificaram a partir do inicio da maturação dos aquênios dos primeiros capítulos (Figura 3).

$\mathrm{O}$ aumento da demanda de $\mathrm{P}$ para a formação dos capítulos e aquênios foi atendido a partir da realocação do $\mathrm{P}$ contido em folhas e caule + ramos, que apresentaram decréscimos a partir de 40 e 50 DAE, respectivamente (Figura 3, Quadro 3). Assim, a disponibilidade de $\mathrm{P}$ nas fases iniciais das plantas foi de extrema importância, em razão do rápido surgimento dos capítulos e consequente formação dos aquênios. Constatações similares foram observadas no trabalho de Zobiole et al. (2010) com a cultura do girassol e no de Mauad et al. (2013) com a cultura do crambe, em que o máximo acúmulo de $\mathrm{P}$ foi obtido na formação e no enchimento dos grãos, uma vez que o $\mathrm{P}$ contido em folhas $\mathrm{e}$ colmos + ramos tem considerável contribuição na formação dos aquênios da oleaginosa.

Levando em consideração a produção dos aquênios, o $\mathrm{P}$ passou a ser o segundo elemento mais requerido pelas plantas. Uma possível explicação para esse fato está relacionada ao acúmulo de lipídios; enquanto para a produção de uma unidade de carboidrato a planta necessita de 1,2 unidade de glicose, para a produção da mesma quantidade de lipídeos essa consome três unidades de glicose (Penning de Vries, 1974). Cabe lembrar que a glicose é quebrada durante a respiração e gera compostos ricos em energia como ATP, que necessita do P para sua síntese.

$\mathrm{O} \mathrm{K}$ foi o nutriente exigido em menores quantidades pelas plantas de niger, tendo em vista que o valor do ponto de máximo de acúmulo de $\mathrm{K}$ foi de 37,03 mg/planta (Quadro 3), aos $70 \mathrm{DAE}$. Comportamento semelhante foi relatado por Mauad et al. (2013), os quais, estudando o acúmulo de nutrientes em plantas de Crambe abyssinica, observaram que o $\mathrm{K}$ foi o nutriente de menor acúmulo por essa oleaginosa.

Quanto à marcha de absorção do K (Figura 3), destacam-se os caules + ramos com 20,26 mg/planta como os órgãos que mais acumularam esse elemento, seguido pelas folhas com $9,19 \mathrm{mg} /$ planta, capítulo com $9,07 \mathrm{mg} /$ planta e aquênios com $2,80 \mathrm{mg} /$ plant (Figura 3, Quadro 3). O capítulo parece ser o dreno preferencial do $\mathrm{K}$, enquanto os caules e ramos são as fontes para essa redistribuição (Quadro 2).

Observou-se que aproximadamente $92 \%$ do $\mathrm{K}$ estavam alocados no caule + ramos, nas folhas e nos capítulos das plantas de niger. Dessa forma, pode-se dizer que a maior parte do $\mathrm{K}$ absorvido pelo niger é passível de retornar ao solo, pois a liberação de $\mathrm{K}$ da palhada é rápida (Rosolem et al., 2006).

$\mathrm{O}$ Ca foi o segundo elemento mais exigido pelas plantas de niger com o máximo acúmulo de 201,86 mg/planta (Quadro 4). Esse nutriente parece ter papel de destaque em oleaginosas, uma vez que Mauad et al. (2013) observaram que para a cultura do crambe o Ca foi o segundo elemento mais exigido, e o mesmo foi relatado por Zobiole et al.(2010) para a cultura do girassol que extraiu $116 \mathrm{~kg} \mathrm{ha}^{-1}$ de Ca.

O a cúmulo de cálcio nos órgãos das plantas seguiu a seguinte ordem: folhas $>$ colmo + ramos $>$ capítulo $>$ aquênio (Quadro 4). Os teores de Ca nas folhas e nos colmos + ramos começam a diminuir a partir de $60 \mathrm{DAE}$, enquanto os teores nos capítulos e aquênios apresentaram pouca variação (Figura 3, Quadro 4). O decréscimo nos teores de Ca nas folhas e no colmo + ramos está relacionado ao menor crescimento e à demanda por esses órgãos, uma vez que o ponto de máxima da curva para a produção de matéria seca ocorreu aos 41 e 50 dias para folha e colmo, respectivamente.

Uma possível explicação para a ausência de queda acentuada nos teores de Ca no capítulo e aquênio (Figura 3, Quadro 4) está relacionada ao crescimento e desenvolvimento da planta de niger. O Ca é um elemento estrutural que participa da constituição da parede celular (Marschner, 2012); assim, durante o ciclo da planta de niger ocorre emissão e formação de vários capítulos que começam a surgir a partir de $30 \mathrm{DAE}$ (Figura 2) e atingem o máximo aos $62 \mathrm{DAE}$ (Quadro 1), isso faz com que ocorra grande demanda de Ca para formação e constituição dos capítulos e aquênios, o que torna esses dois órgãos o dreno principal na planta, mantendo seus teores pouco alteradas até o final do ciclo.

$\mathrm{O}$ acúmulo de $\mathrm{Mg}$ nas plantas de niger seguiu a mesma tendência que para o $\mathrm{Ca}$. O máximo acúmulo desse nutriente foi $66,93 \mathrm{mg} / \mathrm{planta}$ e ocorreu aos 70 dias (Quadro 4). Até 30 DAE, folhas e colmos + ramos apresentaram a mesma contribuição para o acúmulo de $\mathrm{Mg}$ (Figura 3); após esse período, colmos e ramos contribuíram de maneira mais efetiva, com o máximo acumulado de $35,72 \mathrm{mg} / \mathrm{planta}$ aos $67 \mathrm{DAE}$ (Quadro 4). Por serem elementos móveis na planta, colmo e ramos são as principais fontes de $\mathrm{Mg}$ para o capítulo e aquênios (Figura 3, Quadro 2), embora a exportação de $\mathrm{Mg}$ pelos aquênio tenha sido baixa. 
A curva de acúmulo de $\mathrm{S}$ apresentou comportamento muito semelhante ao $\mathrm{Ca}$ e $\mathrm{Mg}$, o ponto de inflexão foi verificado aos $46 \mathrm{DAE}$, bem como o ponto de máxima de acúmulo de nutrientes, aos 66 (Quadro 4). Isso indica que o acúmulo desses nutrientes segue a mesma tendência, variando somente a magnitude da quantidade acumulada, que foi maior para o $\mathrm{Ca}$, seguido pelo $\mathrm{Mg}$. $\mathrm{O}$ acúmulo de $\mathrm{S}$ seguiu a seguinte ordem: colmo + ramos $>$ folhas $>$ capitulo $>$ aquênio.

\section{CONCLUSÕES}

Os teores dos macronutrientes na parte aérea das plantas de niger seguiram a seguinte ordem de exportação de nutrientes: $\mathrm{N}>\mathrm{Ca}>\mathrm{Mg}>\mathrm{P}>\mathrm{K}>\mathrm{S}$. Em contrapartida, quanto aos teores dos nutrientes nos grãos por ocasião da colheita do experimento, a quantidade dos elementos exportados seguiu a ordem: $\mathrm{N}>\mathrm{P}>\mathrm{Ca}>\mathrm{Mg}>\mathrm{S}>\mathrm{K}$.

Atenção especial deve ser dada à manutenção da adequada disponibilidade de $\mathrm{N}$ e $\mathrm{P}$ nas fases inicias em razão do ciclo curto e do rápido surgimento das estruturas reprodutivas.

A exportação de nutrientes e o índice de colheita são baixos para as plantas de niger, resultando maior oferta de nutrientes para o cultivo em rotação.

\section{REFERÊNCIAS}

Ambrosano L. Avaliação de plantas oleaginosas potenciais para cultivo na safrinha [dissertação]. Lavras: Universidade Federal de Lavras; 2012.

Bessa OR, Lima MV, Elias KFM, Fraga AC, Castro Neto P. Rendimento de extração mecânico-química e caracterização físicoquímica do óleo de niger (Guizotia abyssinica). In: Anais do $5^{\circ}$ Congresso Brasileiro de Plantas Oleaginosas, Óleos, Gorduras e Biodiesel [CD-ROM]; 2008; Lavras. Lavras; Universidade Federal de Lavras; 2008.

Empresa Brasileira de Pesquisa Agropecuária - Embrapa. Sistema brasileiro de classificação de solos $3^{\mathrm{a}}$ ed. Brasília, DF; 2013.

Fagherazi S, Dias RL, Bortolon, F. Impacto do exercício físico isolado e combinado com dieta sobre os níveis séricos de HDL, LDL, colesterol total e triglicérides. R Bras Med Esporte. 2008;14:381-6.

Franchini RG. Estudos de sistemas de produção, envolvendo rotação de culturas, com ênfase em culturas para produção de grãos, de óleo e de torta em plantio direto [tese]. Dourados: Universidade Federal da Grande Dourados; 2014.

Franco AAN. Marcha de absorção e acúmulo de nutrientes na cultura do sorgo (dissertação). Janaúba: Universidade Estadual de Montes Claro; 2011.

Getinet A, Sharma SM. Niger, Guizotia abyssinica (L. f.) Cass., promoting the conservation and use of underutilized and neglected crops. Rome: International Plant Genetic Resources Institute, 1996.

Malavolta E, Vitti GC, Oliveira SA. Avaliação do estado nutricional das plantas: Princípios e aplicações. Piracicaba: Potafos; 1997.

Marschner H. Mineral nutrition of higher plants. Amsterdam: Academic Press; 2012.

Mauad M, Garcia RA, Vitorino ACT, Silva RMF, Garbiate MV, Coelho CF. Matéria seca e acúmulo de macronutrientes na parte aérea das plantas de Crambe. Ci Rural. 2013;43:771-8.

Meier H, Reid JSG. Reserve polysaccharides other than starch in higher plants. In: Loewus FA, Tanner W, editors. Encyclopedia of plant physiology. New series. Plant carbohydrates I. London: Springer-Verlag; 1982. 13A. p.418-471.

Penning de Vries FWT. Substrate utilization and respiration in relation to growth and maintenance in higher plants. Neth $\mathrm{J}$ Agric Sci. 1974;22:40-4.

Ramdan MF, Morsel JT. Proximate neutral lipid composition of Niger (Guizotia abyssinica Cass.) seed. Czech J Food Sci. 2002;20:98-104.

Ramdan MF, Morsel JT. Determination of the lip classes and fatty acid profile of Niger (Guizoitia abyssinica Cass.) seed oil. Phytochem Anal. 2003;14:366-70.

Rosolem CA, Garcia RA, Foloni JSS, Calonego JC. Lixiviação de potássio no solo de acordo com suas doses aplicadas sobre palha de milheto. R Bras Ci Solo. 2006;30:813-9.

Sarin R, Sharamaa M, Khanb AA. Studies on Guizotia abyssinica L. oil: Biodiesel synthesis and process optimization. Biores Technol Essex. 2009;100:4187-92.

Staswick PE, Huang JF, Rhee Y. Nitrogen and methyl jasmonate induction of soybean vegetative storage protein genes. Plant Physiol. 1991;96:130-6.

Staswick PE. Storage proteins of vegetative plant tissues. Ann Rev Plant Physiol Plant Mol Biol. 1994;45:303-22.

Taiz L, Zeiger E. Fisiologia vegetal. $5^{\text {a }}$ ed. Porto Alegre: Artmed; 2013.

Werle R, Garcia RA, Rosolem CA. Lixiviação de potássio em função da textura e da disponibilidade do nutriente no solo. $\mathrm{R}$ Bras Ci Solo. 2008;32:2297-305.

Zobiole LHS, Castro C, Oliveria FA, Oliveira Junior A. Marcha de absorção de macronutrientes na cultura do girassol. $\mathrm{R}$ Bras Ci Solo. 2010;34:425-33. 